\title{
MATRIMONIO CIVIL ENTRE PERSONAS DEL MISMO SEXO VS. UNIONES MARITALES DE HECHO EN COLOMBIA Y SU REFERENCIA EN EL DERECHO CIVIL ESPAÑOL ${ }^{1}$
}

\author{
Carlos J ulio Arango Benjumea \\ ProfesorJ efe del Área de Derecho Privado \\ Universidad EAFIT, Medellín
}

\section{Resumen}

La presente reflexión pretende presentar de manera sistemática y descriptiva principalmente el estado actual del matrimonio civil homosexual y de las uniones de hecho de igual carácter en nuestro país con alguna referencia al Derecho de Familia español. La propuesta temática a desarrollar es la siguiente:

1. En cuanto a la unión marital permanente de hecho entre compañeros, mostrar como en Colombia la pretensión de

- Palabras clave: Matrimonio homosexual; Parejas de hecho del mismo sexo; Colombia; España aplicación igualitaria de las normas que regulan la Unión permanente de hecho entre parejas heterosexuales y homosexuales pasa por un tamiz que deja entrever claramente que dicha pretensión es un sofisma de distracción que paradójicamente le hace el juego a una sociedad democráticamente diferenciada entre el que se considera "el orden normal" y "orden anormal" de las apetencias sexuales y afectivas de los ciudadanos.

2. En cuanto al matrimonio civil entre personas del mismo sexo, recordar al respecto la polémica de variada intensidad generada en la mayoría de los países del mundo por su legalización, incluidos aquellos donde existe actualmente protección legal del matrimonio homosexual.

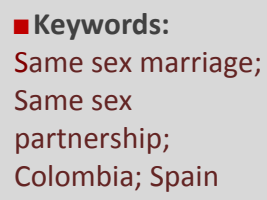

\begin{abstract}
Author shows what is the legal situation of civil same sex marriage at the moment in Colombia and, comparetively, in Spain. In order to complete this explanation, the author offers a detailed exposition about history and present of same sex partnership in Colombia and Spain.
\end{abstract}

${ }^{1}$ La mesa en la que fue pronunciada esta conferencia fue presentada y moderada por el Prof. Dr. José Ramón Narváez Hernández, Profesor del Posgrado en Derecho de la Universidad Nacional Autónoma de México e Instituto de Investigaciones Jurisprudenciales y de Promoción y Difusión de la Ética Judicial de la Suprema Corte de Justicia de la Nación, representante del partner internacional en México y coordinador de la actividad en aquel país. 
I. A modo de aclaración - II. La unión marital de hecho entre compañeros permanentes: Una sola institución jurídica, dos realidades diferentes: 1. Las uniones de parejas homosexuales y el vaivén de la corte constitucional; 2. El matrimonio homosexual una batalla en ciernes; 3 . El Proyecto de Ley 073 de 2010 - III. El matrimonio y la unión marital de hecho de la diversidad de género a la diversidad sexual

\section{A MODO DE ACLARACIÓN}

Sea lo primero señalar que el contraste sugerido entre el Matrimonio y la Unión Marital de Hecho entre personas del mismo sexo, es el resultado del análisis académico sobre dos realidades, tanto jurídicas como sociales, que siendo de calado jurídico diferente, tanto en su génesis, como en su protección legal, dejan ver al mismo tiempo, hilos muy estrechos de unión que permiten afirmar, por lo menos en Colombia, que son dos panoramas jurídicos disímiles pero emparentados en muchas características comunes, lo cual no es un detalle menor como se tratará de evidenciar en el desarrollo del tema, y es por eso que a pesar del trasegar del matrimonio y la unión de hecho por sus propios senderos generando cada uno de ellos situaciones jurídicas concretas y particulares, en algunos eventos relativos a los deberes y a los derechos protegidos se asemejan más de lo que algunos quisieran.

Y lo segundo a tener en cuenta, dado que hay dos auditorios diferentes con formación jurídica propia de sus respectivos ordenamientos jurídicos, el de España y el de Colombia, y que en este último los estudiantes asistentes son todos del primer semestre del pregrado de Derecho, considero necesario la anotación de una diferencia existente en las fuentes de producción normativa del derecho colombiano y el español, para entender las formas de regulación de ciertas situaciones jurídicas y la consagración de instituciones jurídicas como las del matrimonio y las uniones de hecho.

Así las cosas, en Colombia, como Estado unitario que es y no federado, las fuentes que dan origen a las leyes están centralizadas en el Congreso de la República como legislador ordinario, en el ejecutivo como legislador extraordinario; y de manera excepcional la Corte Constitucional que asume funciones colegislativas en ciertos eventos a través de sus fallos de constitucionalidad, razón por la cual nuestra doctrina la denomina legislador negativo. Esas leyes de carácter general son vinculantes en todo el territorio nacional, sin distinción de regiones particulares, costumbres y usos, excepción hecha de la denominada jurisdicción especial, como la indígena y la de las comunidades afrodescendientes a quienes se les reconocen sus propias normas -en algunos asuntos- propias de su organización social interna. Como ley de carácter general tenemos entre otras, al Código civil y las leyes que lo adicionan y reforman. En los departamentos y municipios, entes territoriales de la organización política nacional, las asambleas departamentales y los consejos municipales dictan normas a través de ordenanzas y acuerdos respectivamente, para asuntos propios de cada territorio según competencias señaladas en la constitución y la ley, pero no tienen potestad autonómica para legislar en asuntos de familia como 
el matrimonio, las uniones maritales de hecho, la filiación, la adopción, y en los demás asuntos que competen al estatuto civil, verbigracia contratos civiles y mercantiles, régimen de bienes, la de sucesión por causa de muerte, el estado civil, etc. Todos estos son asuntos del resorte exclusivo del legislador ordinario, como regla general.

En España, si mal no se entiende, bajo un sistema no puramente federado pero sí con las características propias del mismo, en materia jurídico-privada hay coexistencia dentro del territorio nacional de distintos ordenamientos jurídicos, que encuentran su sustento en razones de tipo histórico que devienen fundamentalmente de la Edad Media, lo que da como resultado la convivencia de leyes estatales y leyes autonómicas conocidas como derecho foral o especial, pues la Constitución de 1978, como constitución de consenso que es, reconoce y garantiza la autonomía de las diferentes nacionalidades y regiones que integran la Nación española. De esta guisa, entonces, en España, y como bien lo dice Luis Diez Picazo y Antonio Gullón "en materia civil la regla general de la que hay que partir, en el examen de la materia, es que la legislación civil es materia de competencia exclusiva del Estado, pero "sin perjuicio de la conservación, modificación y desarrollo por las Comunidades autónomas de los Derechos Civiles, forales allí donde existan”. Por tanto, el Derecho Civil foral o especial donde exista, es de competencia de la comunidad autónoma respectiva y no del Estado, con independencia de cuál sea el techo que tenga la autonomía legislativa de tal Comunidad Autónoma según la interpretación más probable.

Se considera entonces, que esta diferencia, nos permite desde Colombia comprender porque las comunidades autonómicas quedan vinculadas, todas ellas, a la normas del matrimonio civil, mientras que con respecto a las uniones maritales de hecho, tanto de parejas heterosexuales como homosexuales, son las comunidades autonómicas que han legislado sobre ello.

Finalmente, los pensamientos y afirmaciones que se acuñan, y que no son todos de la cosecha del conferenciante presente, están dirigidas a la dinámica propia del derecho colombiano con sus aciertos y desaciertos y en algunos pocos asuntos la referencia se extenderá al derecho español, con la corta visión que puede tener quien desde la distancia observa un ordenamiento jurídico que le es ajeno aunque no indiferente, y sí mirado con el respeto que obliga a todo académico, y en el caso personal del autor, con afecto.

Hablar de la familia en la actualidad amerita una apertura de pensamiento y de conciencia que permita visualizar una institución por demás definida en nuestro país a través de una adjetivación bastante genérica "núcleo fundamental de la sociedad”, que da lugar a prédicas ligadas a posturas que se mueven entre extremos ultraconservadores o ultraliberales. En la canónica constitucional colombiana existe el artículo 42 que define la familia: “Art. 42. La familia es el núcleo fundamental de la sociedad. Se constituye por vínculos naturales o jurídicos, por la decisión libre de un hombre y una mujer de contraer matrimonio o por la voluntad responsable de conformarla. Y en otros apartes de la misma norma se dice: ...Las relaciones familiares se basan en la igualdad de derechos y deberes de la pareja y en el respeto 
recíproco entre todos sus integrantes. ...Las formas del matrimonio, la edad y la capacidad para contraerlo, los deberes y derechos de los cónyuges, su separación y la disolución del vínculo, se rigen por la ley civil. ...Los matrimonios religiosos tendrán efectos civiles en los términos que establezca la ley. ...Los efectos civiles de todo matrimonio cesarán por divorcio con arreglo a la ley civil”.

Por lo tanto, partiendo de la declaración que hace nuestra carta política, y mirada textualmente la definición de familia, de un lado se ve claramente que tiene como base primaria el matrimonio heterosexual, valga decir, una base establecida por vínculos jurídicos, exhaustivamente regulada por la ley ordinaria (Código civil y algunas leyes especiales), protegida legalmente a ultranza, generalmente aceptada como una forma de legitimación social; y por otro lado, una base establecida por vínculos naturales surgidos de la decisión libre del hombre y la mujer de conformarla, que tiene su mejor representación en la unión marital de hecho, también protegida y regulada por vía de ley especial, que se integra al Código civil, con un ámbito de protección que alcanza casi los mismos niveles del ámbito matrimonial, pero que todavía guarda algunas diferencias, cada vez menos, pero diferencias al fin y al cabo.

Y entonces cabe preguntarse, ¿̇si en Colombia la Constitución Política consagra la diferencia sexual como requisito esencial de la conformación de la familia matrimonial y no matrimonial, dónde tienen cabida las uniones de pareja del mismo sexo y el matrimonio homosexual, que como consecuencia generarían la formación por vínculos jurídicos o naturales de una familia, homosexual claro está, pero familia al fin y al cabo?

Pues para dar respuesta a esa inquietud por ilustrar la situación y recorrido hecho por las parejas conformadas por dos hombres o dos mujeres que inclusive en muchos casos aportan a la unión sus propios hijos habidos con parejas heterosexuales, o en el caso de algunas las parejas lésbicas habidos por inseminación artificial.

\section{LA UNIÓN MARITAL DE HECHO ENTRE COMPAÑEROS PERMANENTES: UNA SOLA INSTITUCIÓN JURÍDICA DOS REALIDADES DIFERENTES}

En Colombia la unión marital de hecho o como también las denomina la doctrina jurídica, unión de pareja, unión permanente, unión libre o convivencia more uxorio, tanto la formada entre personas de diferente sexo, hombre y mujer, como la establecida entre personas del mismo sexo, mujer-mujer, hombre-hombre, ha pasado por un trasegar histórico intranquilo, nada pacífico, y no solo en el ámbito de la dinámica social, de la conciencia colectiva, sino también en la esfera jurídica, ya legal, ya jurisprudencial.

A nivel histórico se ha ganado amplio terreno en el reconocimiento y en el status socio-jurídico de la unión de hecho o marital heterosexual, que tiene ya un señalado empoderamiento en la sociedad colombiana. 
Es así como de una parte, la Unión de hecho entre un hombre y una mujer en nuestro país rebasó su impronta de ser simplemente un hecho material, del mundo fenoménico, de la realidad, y pasó a virtualizarse en la canónica legal como un hecho jurídico que por ende produce efectos jurídicos, pero aún así en su escalada de legitimidad jurídica, se consagra como una forma opcional de formar una familia, que no se considera strictu sensu una familia legítima por no existir vínculo jurídico, pero que si se legitima ante la ley como familia extramatrimonial y goza de la protección del Estado, tiene su propia normatividad legal que permite la regulación en los efectos personales y patrimoniales.

\section{Las uniones de parejas homosexuales y el vaivén de la Corte Constitucional}

Por lo anteriormente dicho, y de manera preventiva el mismo movimiento LGBT apoyado por el gremio universitario posó su mirada en la Corte Constitucional, la cual mientras el legislador hacía caso omiso de su obligación primaria de legislar para las minorías sexuales, fue reconociendo los derechos a las parejas del mismo sexo por vía de fallos de constitucionalidad condicionada, que tienen fuerza vinculante con carácter general hasta tanto el legislador ordinario regule por vía de ley dichas situaciones desatadas a golpe de sentencias.

Como antecedentes jurisprudenciales importantes a los trascendentales fallos del máximo tribunal constitucional, se consideran los siguientes:

Entre los años 1994 y 2001, época de la llamada primera Corte, denominada así en la doctrina por el hecho que en 2001 hubo un cambio cuantitativo considerable pues de los nueve magistrados que la componen cambiaron siete por retiro forzoso, con un cambio a su vez cualitativo, pues la sensación que se fue formando entre los ciudadanos es que se había pasado de una Corte de rasgo progresista a una más conservadora con posturas menos arriesgadas, por lo menos en lo tocante al tema de la protección a la homosexualidad, pero tal sensación es errónea, porque la Corte en varios períodos se ha movido en medio de crestas ondulantes y entusiastas hacia tal protección y en otras ocasiones se posiciona en el desconocimiento de la misma, con la salvedad que a partir del año 2007 hasta la fecha claramente la tendencia ha sido proteger de manera paulatina las uniones de pareja homosexuales.

En un ligero recorrido histórico se vislumbra al respecto que entre los años 1994 y 1996 "se profirieron siete sentencias sobre derechos de los homosexuales en donde sólo una de ellas fue favorable a las pretensiones del demandante, y aunque no hubo un desarrollo claro de la posición de la Corte Constitucional frente a la homosexualidad si fue un pronunciamiento que abrió la compuerta para que el tema se debatiera públicamente. Se trata de la sentencia T-097 de 1994 con ponencia del Magistrado Eduardo Cifuentes Muñoz, interpuesta por un estudiante expulsado de la escuela de carabineros por practicar actos homosexuales; en esta sentencia la Corte Constitucional ordenó el reintegro por violación al debido proceso. Aquí se puede afirmar que hubo un cierto progreso por parte de la Corte, ya que además de 
favorecer con el fallo al estudiante expulsado dijo que no sería constitucional expulsarlo por ser homosexual. Y si bien el motivo para conceder la tutela fue la violación al debido proceso y no la condición homosexual del tutelante se considera un avance en el tema de los derechos de los homosexuales en Colombia.

Las sentencias desfavorables a las pretensiones de los actores fueron: la sentencia T569 de 1994 (Magistrado ponente Hernando Herrera Vergara) en la cual el demandante abandonó los estudios escolares por no soportar la presión que sufría por acudir a clases con accesorios, maquillaje y prendas femeninas. Para la Corte esta situación del actor puso en evidencia su propia condición sexual encargándose de que su derecho al libre desarrollo de la personalidad no pudiera ser objeto de protección. En la sentencia T-037 de 1995 (Magistrado ponente José Gregorio Hernández Galindo), interpuesta por un estudiante de la escuela de policía sancionado por hacer avances sexuales a un compañero por fuera de la institución, la Corte Constitucional dijo que no procedía la tutela porque el joven incurrió en una falta disciplinaria, así los hechos hubiesen ocurrido fuera de la institución, y aquí la Corte afirma que la homosexualidad es una anormalidad. En la sentencia T-539 de 1994(Magistrado ponente Vladimiro Naranjo Mesa) interpuesta por el abogado Germán Rincón Perfetti en representación de un grupo de homosexuales contra el Consejo Nacional de Televisión por sacar del aire una propaganda en la que salían dos hombres besándose se da una negativa por parte de la Corte argumentando que se trataba de un juicio técnico de conveniencia tomado por el Consejo Nacional de Televisión y no de una violación del derecho a la igualdad, aquí la Corte afirmó que la opción homosexual debía ser tolerada. Con la sentencia T-290 de 1995 (Magistrado ponente Carlos Gaviria Díaz) el discurso de la Corte sobre la homosexualidad cambió. Esta sentencia fue interpuesta por un hombre de condición homosexual al cual el Instituto Colombiano de Bienestar Familiar no le permitía adoptar una menor que estaba bajo su cuidado. La Corte negó la tutela debido a que la decisión del ICBF se basó en las condiciones de vida materiales del demandante que eran físicamente deplorables, más no en la violación de sus derechos. En la sentencia de constitucionalidad C-098 de 1996 con ponencia del Magistrado Eduardo Cifuentes Muñoz, en la cual se resolvió favorablemente la constitucionalidad de la ley 54 de 1990 sobre las uniones maritales de hecho entre heterosexuales se mencionó por primera vez el derecho fundamental a la libre opción sexual, el fallo de esta demanda insistió en que el hecho de que la ley otorgue un beneficio a un grupo desprotegido no significa que esté discriminando a otro (...)”.

A partir de 1998 aparecen una serie de sentencias en las que la Corte protegió a los homosexuales y se demostró una tendencia progresista cuando la norma o el acto demandado admitían que la discriminación se daba por tratarse de un homosexual. La sentencia T-101 de 1998 (Magistrado ponente Fabio Morón Díaz) fue el primer fallo de tutela cuya decisión se fundamentó en la no discriminación de los homosexuales: se ordenó el reintegro de dos jóvenes a quienes se les negó el cupo escolar por ser homosexuales. Luego se presentaron dos fallos de constitucionalidad progresista: la sentencia C-481 de 1998 (Magistrado ponente Alejandro Martínez Caballero), en la cual se declaró inexequible el artículo del Estatuto Docente que establecía que la homosexualidad era causal de mala conducta de los profesores, y la 
sentencia C-507 de 1999 (Magistrado ponente Vladimiro Naranjo Mesa), en la cual se declaró inexequible el artículo del Estatuto Disciplinario de las Fuerzas Armadas que declaraba la homosexualidad como una falta al honor militar.

Luego se presentaron ante la Corte varias sentencias relacionadas con el tema de la afiliación a la seguridad social entre compañeros homosexuales, aquí la Corte en la sentencia T-618 de 2000 (Magistrado ponente Alejandro Martínez Caballero), no resolvió el problema, simplemente se tuteló el derecho al debido proceso, no el derecho a la libre opción sexual. En las sentencias T-999 de 2000 (Magistrado ponente Fabio Morón Díaz) y T-1426 de 2000 (Magistrado ponente Álvaro Tafur Galvis) la Corte simplemente dijo que la afiliación de la pareja homosexual al seguro social no era posible, pues la Constitución no protege la pareja homosexual como familia, por lo tanto no se presenta una vulneración al principio de igualdad.

En el año 2001 comienza la segunda Corte que insiste de manera permanente en que las parejas homosexuales no son aceptables como familia. La Corte respetó el precedente en cuanto a no discriminar abiertamente a los homosexuales y a que éstos no pueden gozar de los derechos de una familia al no poder ser constituida por dos personas del mismo sexo, así en la sentencia SU-623 de 2001 (Magistrado ponente Rodrigo Escobar Gil), reiteró la imposibilidad de afiliar al compañero del mismo sexo a la seguridad social con el argumento de que este derecho sólo es un beneficio familiar y las parejas homosexuales no constituyen familia, luego en la sentencia C-814 de 2001(Magistrado ponente Marco Gerardo Monroy Cabra), se declaró exequible el decreto que establece que para poder adoptar la pareja debe estar conformada por un hombre y una mujer, nuevamente la Corte toma como argumento el hecho de que la pareja protegida por la Constitución es la heterosexual y monogámica.

Pero paradigmáticamente en el mismo año 2001, la Sala civil de la Corte Suprema de Justicia, reconoce por primera vez el derecho de visita íntima de una pareja del mismo sexo en una cárcel. Y más tarde en el 2003 la Corte Constitucional reconoce este mismo derecho haciéndolo extensivo a todas las parejas del mismo sexo"2.

Llegado el año 2007, en el que se hundió en el Congreso de la República de manera definitiva el proyecto de ley 130 de 2005, aparecen las sentencias de Constitucionalidad C-075 (con ponencia de Rodrigo Escobar Gil) y C-811 (con ponencia de Marco Gerardo Monroy Cabra), en las que se reconocieron los derechos patrimoniales y de salud respectivamente a las parejas homosexuales.

Respecto de la primera sentencia, la demanda fue presentada por un grupo de ciudadanos que representaban el colectivo Colombia Diversa, al Centro de Estudios de Derecho, Justicia y Sociedad (De Justicia) formado por profesores universitarios colombianos, y el Grupo de Derecho de interés Público de la Facultad de Derecho de la Universidad de los Andes, y en la que se hicieron reparos a los artículos 1 y 2 parciales de la ley 54 de 1990, modificada por la ley 979 de 2005, valga decir que la Universidad EAFIT intervino a través de varios profesores de su Escuela de

${ }^{2}$ http://es.wikipedia.org/wiki/Homosexualidad_en_Colombia. 
Derecho, coadyuvando la demanda en los siguientes términos: “1. Justificaron la demanda al considerar que eran nuevas las situaciones a determinar, presentándose una cosa juzgada relativa. 2. Sostuvieron que el derecho de asociación resultaba vulnerado para las personas homosexuales al negárseles ser acreedoras de derechos patrimoniales una vez constituidas como pareja.

3. Consideraban que la Corte Constitucional debía apartarse del precedente establecido por la sentencia C-098 de 1996, pues era evidente que la realidad es muy diferente 10 años después, debiendo declararse la inconstitucionalidad de los términos hombre y mujer. Pero la Academia Colombiana de Jurisprudencia defendió la constitucionalidad de la norma, argumentando la cosa juzgada en relación con la sentencia C-098 de 1996, afirmando que las circunstancias que explicaron ese fallo no habían variado debiendo continuar con el precedente. Defendía el concepto tradicional de familia y opinaba, a su vez, que frente a los tópicos en materia laboral, civil y penal que la demanda planteaba, ya se le habían reconocido, analizándolos desde la perspectiva del homosexual individualmente considerado y no como pareja"3.

Fue así como en la sentencia C-075 a través de un análisis jurisprudencial sobre las decisiones que sobre el tema se habían tomando, la Corte señaló que la realidad social colombiana venía dotando de especial importancia la discusión del caso en estudio y que bajo la égida del principio de la dignidad humana el cual postula un deber negativo de no intromisión y un deber positivo de protección y mantenimiento de condiciones de vida digna, se seguía considerar que la regulación patrimonial perteneciente a las parejas de hecho heterosexuales debe ampliarse a las parejas de hecho homosexuales siempre y cuando se cumplan los requisitos exigidos para ser acreedores de los derechos patrimoniales: comunidad de vida permanente y singular por un período no menor de dos años y en consecuencia se declaró la exequibilidad condicionada de la norma demandada.

Pero la misma Corte de manera muy estratégica evitó denominar de manera expresa esa comunidad de vida permanente y singular entre homosexuales como Unión Marital de Hecho homosexual, dejándolos por tanto en la calidad de meros convivientes y no de compañeros permanentes como lo indica la Ley 54 de 1990, y también le hizo el quite al pronunciamiento sobre las parejas homosexuales como un tipo de familia. Y debido a que el fallo desconoció otros derechos relacionados con diferentes áreas del derecho a favor de las parejas del mismo sexo solicitadas en la demanda, el Magistrado Jaime Araújo Rentería hizo salvamento de voto.

Respecto de la sentencia C-811 de 2007 puede decirse que: "Esta sentencia surgió por la demanda de inconstitucionalidad de la expresión 'familiar', contenida en el artículo 163 de la Ley 100 de 1993 (cobertura familiar en salud)... pues dada la imposibilidad de incluir a su compañero homosexual como beneficiario dentro del Plan Obligatorio de Salud cuando se encuentre desempleado, bajo el enfoque

${ }^{3}$ Se resalta esta cita específica del texto Derecho y Diversidad Sexual, entre las otras citas textuales y semitextuales comprendidas en las grandes comillas que se han abierto y se leerá en la conferencia del texto mismo. Página 196, ídem. 
tradicional de familia, se vulneran los derechos constitucionales a la dignidad humana, al libre desarrollo de la personalidad y a la igualdad de trato por parte del Estado, pues se presenta una discriminación por orientación sexual”.

La Corte entonces obró de conformidad con el petitum de la demanda y reconoce los derechos a la cobertura familiar en salud de las parejas homosexuales y, además, aprovechó para referirse a la importancia del precedente judicial en materia de derechos para las parejas homosexuales a partir de la sentencia C-075 de 2007, que equiparó las uniones de pareja heterosexuales y homosexuales fundándose en la realidad social contemporánea y en la protección internacional de la opción sexual del individuo.

En el año 2008 aparece la sentencia C-338 de 2008 (con ponencia de la Magistrada Clara Inés Vargas Hernández). En esta sentencia la Corte consideró que se debía igualar la protección de la que gozaban los compañeros permanentes heterosexuales respecto a la pensión de sobreviviente con las parejas homosexuales, y el tribunal insistió en la necesidad de la intervención del legislador para regular la materia. De nuevo el magistrado Jaime Araújo Rentería hizo salvamento de voto parcialmente por considerar que a la pareja homosexual se le debían reconocer expresamente una protección integral de todos los derechos constitucionales correspondientes. Y, por su parte, el Magistrado Nelson Pinilla Pinilla salvó su voto en sentido contrario al señalar que de conformidad con el concepto de familia consagrado en el artículo 42 de la Constitución las parejas del mismo sexo no hacen parte de ese concepto por lo tanto, no se debían proteger de la misma manera que a las parejas heterosexuales.

En medio de este ambiente caldeado, aparece con ponencia del magistrado Rodrigo Escobar Gil, la Sentencia C-029 de 2009 que decidió la modificación de 42 normas incluidas en aproximadamente 20 leyes, con el fin de lograr una equidad entre parejas heterosexuales y homosexuales, excepto en el asunto de la adopción, sobre lo que la Corte no se pronunció, y de los derechos hereditarios que hasta el día de hoy no se le reconocen todavía ni siquiera a las parejas heterosexuales. De esta manera, la susodicha sentencia de constitucionalidad deja muy bien libradas las uniones de parejas del mismo sexo pues las posiciona a un nivel muy parecido no solo a las parejas de hecho heterosexuales sino al matrimonio mismo, lo que hizo de Colombia, en su momento, un país pionero en América latina al proporcionar un grado tan alto de protección a las parejas homosexuales.

Entre las modificaciones de la sentencia del 2009 están: 1) Los homosexuales tendrán derecho a no incriminar a un compañero permanente, ni a declarar en su contra. 2) En cuanto a los derechos migratorios, podrán recibir la nacionalidad las parejas del mismo sexo que vivan con un extranjero durante más de dos años. 3) Los delitos de violencia intrafamiliar también fueron incluidos para las parejas homosexuales, haciendo la salvedad que la Corte se declara inhibida para incluir o no, a las parejas del mismo sexo dentro del concepto de familia. 4) El Sistema de Salud de las Fuerzas Militares incluirá a las parejas gays en cuanto a pensión de supervivencia y a la condición de beneficiario en salud. 5) Los derechos de

${ }^{4}$ Derecho y sexualidad, ibídem, página 198. 
patrimonio inembargable también incluirán a las parejas homosexuales, lo que significa que una pareja homosexual puede determinar que una propiedad es de ambos y declararla 'patrimonio familiar'. 6) Los homosexuales serán beneficiarios del seguro de vida y del SOAT (Seguro Obligatorio de Accidentes de Tránsito), lo que significa que si uno de los miembros de una pareja homosexual muere, el otro recibirá indemnización. 7) Los funcionarios públicos cuando hagan su juramento de posesión deberán también juramentar a su pareja homosexual, en caso de tenerla”5

Como puede verse, el éxito alcanzado en el reconocimiento de derecho a favor de las parejas del mismo sexo, que nuestra doctrina colombiana reconoce como uniones maritales de hecho, pues no es otra la consecuencia de las protecciones obtenidas las cuales deben necesariamente tener como sustento ontológico dicha figura jurídica regulada y desarrollada como institución, deja de todas maneras un sinsabor, pues los reconocimientos señalados no provienen del centro de producción normativa natural que es el legislador en uso de su poder ordinario atribuido por el constituyente primario, sino que se ha tenido que acudir a la esfera de la jurisprudencia constitucional como forma subsidiaria de protección.

Entonces cabe la pregunta, ¿si será que hay tal igualdad en Colombia entre las parejas hetero y homosexuales cuando el legislador mismo desconoce por su inapetencia e incompetencia su obligación constitucional de reconocer los derechos de todos los ciudadanos colombianos, incluidos los que se agrupan en minorías excluidas?

Lo más optimistas responde que sí, pues solo basta el reconocimiento a la adopción y los derechos hereditarios en las parejas homosexuales para que esta opción se convierta en algunos casos inclusive mejor que el matrimonio, pues no tendría las desventajas de amarre que tiene el mismo y sí todas las ventajas que de él se pregonan en los tiempos actuales.

\section{El matrimonio homosexual una batalla en ciernes}

Igual que en el derecho español, la Constitución Política de Colombia se refiere a la institución del Matrimonio. La consagración se hace en el Título II, dedicado a la consagración de los derechos, garantías y deberes de los ciudadanos, específicamente en el Capítulo II que está dedicado a los derechos sociales, económicos y culturales y que se abre con el artículo 42. Es de anotar, que la consagración de la institución del matrimonio quedó normativamente ubicado en sede de los derechos y deberes de la institución familiar, toda vez que uno de los pilares fundamentales de la familia es el matrimonio.

También, de igual manera que en el derecho hispano, la Constitución Política remite a la ley civil para efectos de regular las formas de matrimonio, la edad y capacidad

${ }^{5}$ http://www.agmagazine.com.ar/versionImprimible.php?IdNot=3407. En Artículo "Colombia: la Justicia amplía los derechos de las parejas homosexuales”, por Manuel Velandia. 01-282009. 
para contraerlo, los deberes y derechos de los cónyuges, su separación y disolución del vínculo, pero a diferencia del derecho español en el ordenamiento jurídico colombiano no se consagra de manera expresa el ius connubi, pues no existe una norma como la del artículo 32.1 de la CE y su correlativa expresión legal en el artículo 44.1 del Código civil, que señale el derecho de los cónyuges a contraer matrimonio en igualdad jurídica y de conformidad a las disposiciones legales, se trata pues en España de una regla que vincula a todos los poderes públicos y cuyo contenido esencial está protegido por la acción de inconstitucionalidad. Ahora bien, del canon constitucional colombiano (artículo 42, incisos 1 y 2 se concluye el ius connubi en la expresión: "La familia es el núcleo fundamental de la sociedad". Se constituye por vínculos jurídicos, por la decisión libre de un hombre y una mujer de contraer matrimonio... Así pues, el enunciado que indica que se trata de una unión libre de un hombre y una mujer a contraer matrimonio contiene en sí misma el derecho de contraer matrimonio libremente, y ello implica la consagración tácita del ius connubi con rango constitucional. Y a nivel legal, dicho derecho aparece consagrado en el artículo 115 del Código civil Colombiano, cuando manifiesta que el contrato de matrimonio tiene como fundamento el libre y mutuo consentimiento de los contrayentes. Así, pues, de estas dos disposiciones jurídicas que tienen su refugio en otros dos cánones constitucionales a saber los artículos 13 y 16 CP se desprende la libertad de contraer matrimonio configurado como un derecho al matrimonio, es decir, el ius connubi.

Igualdad que se reproduce legalmente de manera expresa en el artículo 66 del Código civil español al señalar que los cónyuges son iguales en derechos y en deberes, todo ello respaldado por el canon constitucional 14, haciendo eco de la no discriminación, entre otras razones, por la del sexo. Por su parte en la Constitución colombiana no hay un canon constitucional que consagre de manera expresa la igualdad jurídica entre marido y mujer, pero sí está el artículo 43 que señala, de manera genérica y amplia, la igualdad de derechos y oportunidades entre la mujer y el hombre, con la correlativa consagración, todavía mucho más omnicomprensiva, del canon 13 que es un culto al principio de igualdad jurídica y material, pues da las pautas para su aplicación real y efectiva. La consagración legal de la plena igualdad jurídica de los cónyuges no se da en términos de norma expresa pero sí por el sentido diáfano que arrojan las consagraciones de la ley 28 de 1932 y del Decreto 2820 de 1974, pues a través de la primera normatividad desapareció la sujeción de la mujer al marido en asuntos relacionados con la administración de los bienes de la sociedad conyugal, y por la segunda se declaró la muerte de la potestad legal marital que tenía el marido respecto de su mujer.

También, a diferencia del derecho español, en Colombia el Código civil define en su artículo 113 el matrimonio como un contrato que se celebra de manera exclusiva entre un hombre y una mujer y a través del cual se comprometen a vivir juntos, a procrear y a auxiliarse mutuamente. Por tanto, de la enunciación legal se determina claramente la naturaleza contractual de la unión matrimonial, y de igual manera su contenido jurídico esencial frente al que se advierte que salta de bulto la exclusión de una característica propia del matrimonio canónico, cuál es la indisolubilidad del vínculo. 
Así las cosas, tanto el matrimonio civil, objeto de nuestro estudio, como el matrimonio religioso se establece sobre la base intersexual, debe ser contraído por un hombre y por una mujer, y es claro que respecto al matrimonio religioso, y específicamente el matrimonio católico, no hay que dar mayores explicaciones para esa exigencia, pero de igual manera en nuestro país el matrimonio civil está configurado, hasta la fecha, bajo el supuesto de la diferencia de sexos, pues ello lleva a la Corte Constitucional Colombiana a señalar hasta la fecha que entre los efectos civiles del matrimonio están, entre otros, la legitimidad de la prole, partiendo del supuesto que la procreación se da a través de la unión sexual del hombre y la mujer.

No se ha aceptado en este país caribeño el matrimonio entre personas del mismo sexo, es un requisito sine qua non de carácter objetivo la diferencia de sexos, que como lo señala Juan Enrique Medina Pabón, a primera vista se verifica con las características físicas de un individuo de la raza humana que sea hombre y el otro que sea mujer, sin importar si su psiquis corresponde a la del sexo contrario, o que sus órganos reproductivos sean normales o presenten alguna anomalía, o que sus preferencias sexuales se muevan en el continuo de la sexualidad humana o su capacidad reproductiva o capacidad física y afectiva para realizar el acto sexual. De hecho el funcionario competente establece el sexo de los contrayentes a través de los correspondientes certificados de nacimiento que provee el registro del estado civil.

Por su parte, en Colombia igual que en muchos países del orbe, se ha dado la discusión respecto del matrimonio homosexual, pero a diferencia de países como Suecia, Noruega, Dinamarca, España, entre otros, que han extendido las reglas del matrimonio a las parejas del mismo sexo, ni el legislador colombiano ni la Corte Constitucional han optado por tal reconocimiento y extensión, advierto de nuevo que hasta la fecha. Y de hecho, los movimientos sociales que han surgido para efectos del reconocimiento de las parejas del mismo sexo, han dejado de lado y ex profeso el propósito de impulsar el reconocimiento del matrimonio para las parejas homosexuales y se han dedicado, de manera denodada y con visibles resultados, al reconocimiento y aplicación del régimen de las uniones maritales heterosexuales a las uniones homosexuales. Claro está, que esto varió con la demanda de constitucionalidad que cursa actualmente en la Corte respecto de la definición de matrimonio del artículo 113 del Código civil, de la cual estamos esperando en los próximos días el pronunciamiento respectivo que puede partir en dos la historia del derecho matrimonial en Colombia y de contera la historia del derecho de familia patrio.

Pues bien, y llegando al núcleo esencial del matrimonio y por supuesto del consentimiento matrimonial es de advertir que de conformidad con los artículos 176, 177, 178, 179, 180, 251, 252, 253 y 257 del Código civil, se desprenden los derechos y las obligaciones matrimoniales, de los cuales hablaré más profundamente también en el capítulo siguiente, pero que se enuncian así: El deber de fidelidad y exclusividad, el deber de socorro y ayuda mutuos, que tiene un soporte tanto personal como patrimonial, el deber de cohabitación, el deber de fijar el domicilio común conyugal, el deber de establecimiento y dirección del hogar, que incluye la subvención de las ordinarias necesidades domésticas, el cuidado personal y la 
custodia con la facultad de vigilancia, control, corrección y sanción moderada, y la subvención de los gastos de la crianza y educación de los hijos comunes, aunque se encuentren en estado de separación de bienes, lo que se verifica a través del cumplimiento de la obligación alimentaria (vestido, alimentación, educación, salud, habitación y recreación), y finalmente la adecuada administración y manejo del caudal patrimonial social a cuyo cargo están los dichos gastos respecto a los hijos, y también respecto al establecimiento de los cónyuges y de los padres y a los ascendientes, que en estado de ancianidad, demencia y otras causas requieran auxilio. En España por su parte además, del divorcio y la separación de mutuo acuerdo, o el divorcio y separación solicitado por uno de los cónyuges con consentimiento del otro, que es una derivación del primero, tienen el denominado divorcio no causal o exprés, determinado por la decisión unilateral de unos de los cónyuges una vez hayan transcurrido tres meses de celebrado el matrimonio, ello consagrado por la Ley 15 de 2005, que modificó el Código civil y la Ley de enjuiciamiento civil en estas materias.

En este marco de acción aparece la referida demanda de constitucionalidad de la cual se destaca lo siguiente: Fue presentada por el ciudadano abogado Felipe Montoya Castro, quien se manifiesta de la siguiente manera:

“... me dirijo a ustedes para interponer acción pública de constitucionalidad contra las expresiones "un hombre y una mujer" y "de procrear" contenidas en el articulo 113 del Código civil de Colombia, y contra las expresiones "familia” y "un hombre y una mujer de contraer matrimonio" contenidas en el inciso I del artículo 2 de la Ley 294 de 1996. Las normas demandas vulneran los mandatos constitucionales contenidos en los artículos 1, 2, 11, 12, 13, 16, 18 y 38 de la constitución política, y normas que integran el bloque estricto de constitucionalidad conformado en el caso concreto, por el artículo 1 de la convención americana sobre derechos humanos y el artículo 6 de la declaración americana de los derechos y deberes del hombre.

Solicitud a la H. Corte Constitucional:

Respecto al artículo 113 del Código civil de Colombia, Solicito que se declaren inconstitucionales las expresiones "un hombre y una mujer” y "de procrear” por las razones expuestas en la demanda.

Respecto a las expresiones "familia” y "un hombre y una mujer de contraer matrimonio” contenida en el inciso I del artículo $2^{\circ}$ de la Ley 294 de 1996, solicito sean declaradas inexequibles por las razones expuestas en la demanda.

Texto de las normas demandadas:

Artículo 2 de la Ley 294 de 1996: La familia se constituye por vínculos naturales o jurídicos, por la decisión libre de un hombre y una mujer de contraer matrimonio o por la voluntad responsable de conformarla. Para los efectos de la presente Ley, integran la familia. Los cónyuges o compañeros permanentes: (...). 
Artículo 113 del Código civil: El matrimonio es un contrato solemne por el cual un hombre y una mujer se unen con el fin de vivir juntos, de procrear y de auxiliarse mutuamente"

Cabe destacarse de la demanda dos apartes de la Exposición de Motivos o Fundamentos de la Demanda Interpuesta, así el primero relacionado con el concepto de familia respecto de la que argumenta el demandante que "La familia no es una comunidad de individuos, sino unos determinados sujetos que la constituyen en virtud de las relaciones que les unen. Antes que sociales, estas relaciones son personales, es decir, constituyen la intimidad de la persona. Desde el punto de vista de la antropología filosófica, "la noción de familia está ligada a las nociones de persona -como único sujeto digno de ser querido por sí mismo-; de comunión de personas -fruto del amor interpersonal-; y de relación.

Familiar. Las relaciones familiares no son meros accidentes (en el sentido filosófico) de la persona, sino que pertenecen a la esencia de la estructura empírica de la vida humana, tal como ésta se da en la existencia”. En esta lógica de pensamiento vemos como el deseo humano de constituir una familia no obedece al simple capricho de un individuo sea éste homosexual o heterosexual sino que obedece a la naturaleza humana y a la esencia intrínseca de las personas. Ha sostenido la Corte Constitucional que "Es un principio axial del Estado Social de Derecho, liberal, la neutralidad del Estado frente a los planes de vida buena de los asociados (...); en esa clase de organización política, el hombre no es un medio al servicio del Estado en la búsqueda de objetivos comunes, sino un fin en sí mismo, libre para buscar su propia meta de perfección. Así, el orden político justo que debe ser aquél a cuya realización debe propender el Estado Colombiano”. Y respecto del segundo concepto, relacionado con el matrimonio señala el libelista:

“Dice la norma objeto de la demanda, Artículo 113 del Código civil: El matrimonio es un contrato solemne por el cual un hombre y una mujer se unen con el fin de vivir juntos, de procrear y de auxiliarse mutuamente. (...) No nos debe quedar pues duda que el matrimonio religioso y el matrimonio civil son dos figuras completamente diferentes y respecto de las cuales no se puede aplicar la figura de la analogía para hacer extensivo al orden civil el requisito religioso de la heterosexualidad de los contrayentes, pues los derechos de asociación, libre desarrollo de la personalidad, dignidad humana e igualdad son inherentes a toda persona y a nadie se le puede negar la posibilidad de recurrir a la figura contractual del matrimonio civil si a bien lo tiene y ello es concordante con su plan de vida. Bélgica, Canadá, España, Noruega, Países Bajos, Sudáfrica y Suecia han permitido a las parejas del mismo sexo acudir al matrimonio, entendido como contrato civil. También han actuado en forma similar los estados de Massachusetts y Maine en Estados Unidos. (...) Esta, sin lugar a dudas es la óptica que mejor se ajusta a nuestro Estado Social de Derecho de carácter pluralista e incluyente ${ }^{7}$.

\footnotetext{
${ }^{6}$ Felipe Montoya Castro. Demanda en acción pública de constitucionalidad. Páginas 1, 2.

${ }^{7}$ Felipe Montoya Castro. Op.cit. páginas 3, 11, 12, 13.
} 
De esta guisa, conocemos que la demanda está en el despacho de la Magistrada Clara Inés Vargas Hernández, quien ha tenido posiciones a favor del reconocimiento de los individuos homosexuales y de las parejas homosexuales, aunque sus pronunciamientos al respecto se caracterizan de ser tímidos y prudentes. La Magistrada mira con buenos ojos la situación de la minoría sexual homosexual, pero adelantar sobre ello la orientación del fallo de constitucionalidad es prematuro. Se sabe que instó a la intervención de la ciudadanía, invitación que fue recogida por más de cincuenta intervenciones, entre ellas las de aproximadamente 10 universidades colombianas, varias ONG [Organizaciones no gubernamentales], La Conferencia Episcopal Colombiana, los diferentes organismos del Estado, los partidos políticos, organismos multilaterales como la ONU [Organización de Naciones Unidas].

La posición más recalcitrante sobre el tema la sigue sosteniendo el Procurador General de la Nación, en cabeza del señor Alejandro Ordoñez Maldonado, quien sigue oponiéndose a la solicitud del reconocimiento de derechos a las parejas del mismo sexo como familia y ahora con mayor razón a la posibilidad de contraer el vínculo matrimonial, esgrimiendo como argumento central "la procreación” y la "supervivencia de la raza humana" que tiene como base fundante la diferencia de sexos.

La verdad sea dicha, no se sabe en estos momentos en Colombia cuál será la reacción de la Corte Constitucional frente al reconocimiento del matrimonio homosexual por vía de Constitucionalidad, toda vez que la reestructuración que se ha seguido dando en el alto tribunal con la llegada de nuevos magistrados impide saber con cierto grado de certeza cuál será su posición al respecto, ya que de algunos de ellos no se conocen pronunciamientos en este campo. El sector abanderado del reconocimiento mencionado tiene muy afincadas sus expectativas a favor del mismo; un gran sector de la población se opone a través de organizaciones seculares, la mayoría de ellas de corte cristiano apostólico romano, y un tanto no cuantificable claramente guarda un silencio también expectante.

Es claro que en el ámbito universitario, con denotadas excepciones, hay un ambiente propicio a favor de las peticiones de la demanda y de los argumentos que las apoyan. Por tanto, ante la incertidumbre propia de la situación subiudice sería temerario adelantar hipótesis sobre el cambio de panorama que se avecina con el cambio de paradigma si fructifica el esfuerzo que recoge la demanda analizada.

\section{El proyecto de Ley 073 de 2010}

Como se anunció, quedó reservado para la parte final de la conferencia el obligado comentario sobre el proyecto de Ley 073 de 2010, que fue presentado ante la Secretaría General del Senado de la República el pasado 4 de agosto, liderado de nuevo por la Senadora Piedad Córdoba Ruíz. 
En cuanto a la propuesta que hace el Proyecto de Ley, hay que decir que de manera general recoge las principales pretensiones que tuvieron los ya mencionados proyectos de Ley 85 de 2001 y 43 de 2002 que habían sido presentados para su trámite legislativa por la misma senadora Piedad Córdoba Ruíz.

Cabe destacar de los ocho (8) artículos que componen el proyecto, los siguientes aspectos de interés:

1. Que en la denominación del proyecto actual, 73 de 2010, hay un ligero cambio en el enunciado respecto de los proyectos anteriores, y que parece una mera circunstancia formal, pero que tiene incidencia importante en el fondo o contenido del mismo. Así, tanto el Proyecto 81 como el 43 susodichos, se enunciaban como "Por el cual se reconocen uniones de parejas del mismo sexo, sus efectos patrimoniales y otros derechos", mientras que el actual proyecto se encabeza así: "Proyecto de Ley 73 de 2010 Senado, por la cual se reconocen las uniones de parejas del mismo sexo y sus efectos legales”. Es claro, por tanto, que el énfasis que se le hicieron a los proyectos anteriores abortados, era el aspecto patrimonial de las uniones de hecho a más del reconocimiento de las uniones homosexuales como tal, tanto así que en los textos de los artículos $5^{\circ}$ numeral 1 (Proyecto 81 de 2001), y $4^{\circ}$ (Proyecto 43 de 2002) se consagraba la creación de un régimen patrimonial especial para las parejas del mismo sexo, sin que se llegara a confundir con el régimen patrimonial vigente de las parejas heterosexuales reguladas por la Ley 54 de 1990, no admitiéndose su aplicación analógica ni para su constitución, ni para administración, disolución y liquidación, ya que el trámite era propio y en el evento de su judicialización se llevaba al conocimiento del Juez Civil y no de Familia como corresponde a las uniones maritales de diferente sexo. Por su parte, en el artículo $4^{\circ}$ del proyecto actual como obedece al enunciado inicial de reconocer a las uniones homosexuales sus efectos legales, y entre ellos, los patrimoniales en igualdad de condiciones constitucionales y de orden legal de los demás derechos, se procede a presumir, la sociedad patrimonial de hecho prácticamente en las mismas condiciones que se aplican en el régimen de la Ley 54 de 1990, siempre que se cumpla con la realización del supuesto de hecho normativo consistente en que haya convivencia por un lapso no inferior a los dos años y que las sociedades conyugales o patrimoniales anteriores hayan sido disueltas y liquidadas por lo menos un año antes de la iniciación de la unión. Como se ve, se ha resaltado la expresión "prácticamente en las mismas condiciones", porque en el proyecto se exige que la disolución sea tanto de sociedades conyugales como de sociedades patrimoniales anteriores, mientras que en el artículo $2^{\circ}$ de la ley 54 de 1990, literal b), solo se exige la disolución de las sociedades conyugales y no las patrimoniales anteriores. Claro que al respecto nuestra doctrina ha diagnosticado que en el evento de presentarse tal situación de una sociedad patrimonial de hecho anterior en una unión marital heterosexual debe aplicarse analógicamente el requisito de ley exigido para la existencia de una sociedad conyugal, punto todavía discutible.

Dice además el proyecto, en el mismo artículo $4^{\circ}$ que la sociedad patrimonial de hecho podrá ser declarada judicialmente, o por el mutuo consentimiento expresado en escritura pública ante notario o por acta suscrita ante un centro de conciliación previa la demostración de la existencia de los requisitos que se exigen en dicho artículo. Con ello se recogen, en este sentido, los lineamientos de la Ley 54 de 1990 
modificada por la Ley 979 de 2005, y de la Ley 962 del mismo año que le confiere competencia a los notarios para la constitución de la sociedad patrimonial de hecho entre compañeros permanentes.

Ahora, igual que como sucede en el régimen de conformación de la sociedad patrimonial de hecho de las parejas heterosexuales, el proyecto replica textualmente en su artículo $5^{\circ}$ el artículo $3^{\circ}$ de la Ley 54 , pues se señala:

“Artículo 5․ Bienes de la sociedad patrimonial. El patrimonio o capital producto del trabajo, ayuda y socorro mutuos pertenece por partes iguales a ambos compañeros.

No forman parte del haber de la sociedad patrimonial de la pareja del mismo sexo los bienes adquiridos en virtud de donación, herencia o legado, ni los que se hubieren adquirido antes de iniciar la unión, pero sí lo serán los réditos, rentas, frutos o mayor valor que produzcan estos bienes durante la unión, salvo pacto en contrario de las partes”. (Subrayado extratexto, pues son las dos adiciones que les hace el proyecto a la norma de la ley 54 de 1990).

Necesario aquí es advertir que la Senadora Córdoba Ruiz y el ponente para primer debate, Senador Moreno Rojas, no tuvieron en cuenta aclarar que la expresión “o mayor valor que produzcan estos bienes durante la unión marital de hecho" ha sido objeto un pronunciamiento de exequibilidad condicionada por parte de la Corte Constitucional, mediante la sentencia C-14 de 1998 en la que se dijo que la expresión se mantenía “...bajo el entendido de que la valorización que experimentan los bienes propios de los convivientes, por causa de la corrección monetaria no forma parte de la sociedad patrimonial”. Claro que como se dirá en un momento, esta omisión se suple con la interpretación que se haga del artículo $7^{\circ}$ del proyecto.

Y como corolario de lo anterior, el artículo $6^{\circ}$ ibídem, hace una remisión expresa a la analogía legis al señalar que "además de lo previsto en esta ley, la sociedad patrimonial de la pareja del mismo sexo se regirá por lo dispuesto en la Ley 54 de 1990 y las normas que la modifiquen, adicionen o reformen”.

2. Al definir el proyecto la unión de pareja del mismo sexo, lo hace utilizando la estructura genética de la misma, igual que lo hizo la Ley 54 de 1990 respecto de la unión heterosexual, pero con diferencia de algunas expresiones semánticas, tanto en el enunciado de la ley como en el enunciado del proyecto, ya referido en el acápite anterior pero con otro nivel relacional (se compararon los tres proyectos de un mismo tema - 85 de 2001, 43 de 2002 y 73 de 2010. Y a sabiendas de la susceptibilidad nacional que genera el tema, tal definición y enunciación puede dar lugar a discusiones bizantinas que pretenderán mantener diferencias sustanciales entre ambas figuras, so pretexto del empleo de expresiones equivalentes pero no iguales.

Veamos, la Ley 54 de 1990 se enuncia y define así: “...por la cual se definen las uniones maritales de hecho y régimen patrimonial entre compañeros permanentes. Artículo $1^{\circ}$. A partir de la vigencia de la presente Ley y para todos los efectos civiles, se denomina Unión Marital de Hecho, la formada entre un hombre y una mujer, que sin estar casados, hacen una comunidad de vida permanente y singular. 
Igualmente, y para todos los efectos civiles, se denominan compañero y compañera permanente, al hombre y la mujer que forman parte de la unión marital de hecho”. (Subrayado extratexto).

El proyecto se enuncia y define así:

“...por medio de la cual se reconocen las uniones de parejas del mismo sexo y sus efectos legales. Artículo $1^{\circ}$. Objeto: La presente ley tiene por objeto reconocer legalmente los derechos y deberes de las uniones maritales de las parejas del mismo sexo, dentro del marco de igualdad y respeto a la diferencia que establece la Carta Política. Artículo $2^{\circ}$. Conformación. Son uniones de parejas del mismo sexo las formadas entre dos personas mayores de edad, que hacen una comunidad de vida permanente y singular, que corresponden al mismo sexo, siempre que ninguna de ellas tenga vínculo conyugal, unión marital de hecho o unión de pareja del mismo sexo u otro distinto, vigente”. (Subrayado extratexto).

Todas las expresiones que aparecen resaltadas con líneas en un sentido amplio están haciendo eco de un tratamiento sinonímico entre uniones maritales de hecho y uniones de pareja, de igual o diferente sexo, aunque un purista del lenguaje podría llegar a decir que no son lo mismo, y que cuando el legislador distingue el intérprete debe distinguir, lo que indica que en el proyecto de ley se debió cuidar de emplear el mismo término "Unión marital de hecho" para las personas del mismo sexo, como se hizo en la Ley 54 de 1990, y no solo en el sentido de señalar por vía negativa, en la parte final del artículo $2^{\circ}$, que habrá unión de pareja del mismo sexo siempre que ninguna de las dos personas que la conforman tenga "unión marital de hecho o unión de pareja del mismo sexo u otro distinto, vigente”. Nada raro sería que se pretenda sostener que el conector "o" entre las expresiones "unión marital de hecho" "Unión de pareja del mismo sexo" sea de naturaleza disyuntiva y no copulativa, para acotar, además que por eso el artículo habla de "otro distinto sexo". De interpretaciones forzadas hay bastante acervo doctrinal e inclusive jurisprudencial.

De igual manera, en lo relativo a la expresión “compañeros permanentes”, pues en la definición de la normativa legal (Ley 54 de 1990) se definen también claramente quiénes son compañero y compañera permanente, es decir, “el hombre y la mujer que sin estar casados ,hacen una comunidad de vida permanente y singular”, mientras que en el proyecto nada se dice al respecto, y solo hay un uso de la expresión "los compañeros" en el artículo $4^{\circ}$ respecto de la declaración de la existencia de la sociedad patrimonial de hecho.

3. El otro aspecto relevante, que igual se dicta en la definición es el concerniente a la capacidad de las personas que pueden conformar una unión marital de hecho del mismo sexo, pues hay una exigencia expresa de "la mayoría de edad" de ambos hombres o ambas mujeres, que es un requisito no existente en la sociedad patrimonial de hecho heterosexual.

Como ya se expresó en el contenido de esta conferencia, y respecto del tema de la capacidad, no hay un requisito de edad expreso de ley para conformar la unión marital entre un hombre y una mujer, salvo el límite que la naturaleza misma 
impone para efectos de proteger la integridad física y moral de la infancia y la adolescencia temprana, que va desde los cero (0) hasta los catorce (14) años), lo que sigue estableciendo entonces una discriminación por razón de la orientación sexual, pues significa que un incapaz relativo, como un menor adulto, varón o mujer, de diecisiete (17) años por ejemplo no podrá conformar lícitamente una unión marital de hecho, mientras que en la misma situación o con una edad menor que no esté por debajo de los catorce (14) años sí puede legítimamente contraer matrimonio civil o religioso, con una persona mayor de edad, no importa la diferencia que entre ellos existe, o con una de su misma edad, teniendo solo como sanción el desheredamiento, o en su defecto la declaración de indignidad, si no solicitó por parte de los ascendientes que indica la ley para obtener su autorización ${ }^{8}$.

Se pregunta entonces ¿qué se pretende proteger con dicho límite de la mayoría de edad: impedir que un posible miembro de la pareja, mayor de edad, o un menor adulto bastante maduro, se aproveche indebidamente del menor o la menor con la cual forma la unión marital, para efectos de lucrarse patrimonialmente de forma indebida de los bienes de dicho incapaz, o que lo someta a tratos inmorales, depravados e ilícitos? A lo que se respondería con otra pregunta: ¿Acaso el matrimonio legítimamente celebrado evita que el incapaz quede sometido a esas vejaciones o abusos patrimoniales? La respuesta es: No y para ello existen las acciones de la ley tanto penal como civil que se pueden impetrar en protección de dicho sujeto, ya por el mismo, por el ministerio público o en su defecto por un representante nombrado específicamente para ello.

Se aclara, que no se pretende hacer apología a una libertad sexual temprana y desbordada, solo que al aplicar el principio de hermenéutica material que no indica: donde existe las mismas razones de hecho, se deben dar las mismas consideraciones de derecho, queda claro que hay un trato desigual en este tema de la capacidad, que como bien se ve amerita un análisis más completo.

Como consecuencia de lo anteriormente referido, es conclusión lógica y necesaria, pensar que la interpretación que debe hacerse de todo el articulado del proyecto debe ser guiado a más del sentido literal de la norma por su sentido lógico-jurídico y finalista-consecuencialista, pues no basta utilizar meramente el elemento gramatical, so pretexto de la claridad enunciativa del texto legal, sino que hay que hacer una lectura integral y armónica de todo el texto propuesto. Y para ello el penúltimo artículo trae de nuevo una herramienta ya acotada, la analogía legis, que permite llenar los vacíos y oscuridades latentes en el proyecto, al señalar: “Artículo $7^{\circ}$. Otros efectos. Son aplicables a la unión de personas del mismo sexo y a sus integrantes las leyes civiles, penales, laborales, administrativas y de cualquier otro orden aplicables a la unión marital de hecho y a los compañeros permanentes, entre ellas las que determinan o les atribuyen derechos, deberes, prohibiciones, limitaciones, cargas

${ }^{8}$ Protección a los menores de catorce (14) años y que es recogida por los artículos 208, 209 y 211 de la Ley 599 de 2000 (Código Penal), artículos 192 a 200 de la Ley 1098 de 2006 (Código de Infancia y Adolescencia), el parágrafo del artículo 53 la Ley 1306 de 2009 sobre Régimen de Discapacidades, y la Sentencia de la Corte Constitucional C- 534 de 2005 con ponencia del Magistrado Humberto Antonio Sierra Porto. 
sustanciales o procesales, inhabilidades, incompatibilidades, conflictos de intereses, impedimentos, recusaciones y medidas de protección”. (Subraya extratexto).

Se resalta de nuevo una expresión como la de las leyes las leyes civiles, penales, laborales, administrativas y de cualquier otro orden aplicables, pues es de parecer del conferencista que tal expresión debía adicionarse con la "de las normas” y quedara el texto así: “... las normas y las leyes civiles, penales, laborales, administrativas y de cualquier otro orden aplicables...." que permitan el uso analógico de los cánones constitucionales, las sentencias de constitucionalidad que los interpretan y aplican, y las sentencias de unificación de tutela y de tutela proferidas por el Juez Constitucional, las Sentencias de la Corte Suprema de Justicia y las análogas del Consejo de Estado, junto con los demás actos que permitan su aplicación a esta realidad de la unión homosexual.

Y como dato curioso, hay un error de digitación, seguramente, en el proyecto de ley y la ponencia para primer debate al hablar de la importante sentencia C- 029 de 2009, ya también analizada, y que se menciona erradamente como la Sentencia C- 079 de 2009.

Por lo demás, hay que mirar con optimismo el futuro de las naciones y de los Estados de Derecho que las protegen y regulan. Por ello, no está de más un voto de confianza en el legislador colombiano en aras a un cambio de mentalidad que permita el ejercicio de una política pública legislativa incluyente, en la que se consolide la confianza del pueblo en su órgano legislativo democráticamente elegido, al que le ha delegado la sagrada misión de proteger, a través de las leyes que produce, la protección tanto de los grupos mayoritarios como de aquellos que por su escasa representación o minoridad se ven excluidos y marginados, advirtiendo en todo momento, y a la luz de lo dicho por el alto Tribunal Constitucional en la Sentencia C-507 de 2004, que trae a colación en la exposición de motivos la senadora Córdoba Ruíz en su proyecto: que "no le corresponde al juez constitucional sustituir la apreciación del legislador ni imponer niveles de protección máximos o ideales. No obstante, sí le compete determinar (i) si el legislador no ha respetado los mínimos de protección constitucionalmente ordenados, (ii) si la desprotección de un grupo excede los márgenes constitucionalmente admisibles, o (iii) si la menor protección relativa de un grupo obedecen a una discriminación, lo cual estaría constitucionalmente prohibido”.

\section{EL MATRIMONIO Y LA UNIÓN MARITAL DE HECHO DE LA DIVERSIDAD DE GÉNERO A LA DIVERSIDAD SEXUAL ${ }^{9}$}

Para finalizar el panorama de la unión marital de hecho entre personas de diferente sexo, se quiere llamar la atención, de manera especial, respecto del requisito uno 1) del surgimiento de la unión marital de hecho enunciado como diversidad de sexos,

${ }^{9}$ Anexo esta reflexión adicional como un punto que puede dar lugar a otras reflexiones de carácter interdisciplinar, que pueden resultar útiles en un futuro cercano si tanto la demanda sobre el matrimonio homosexual como el proyecto de ley sobre unión marital de hecho entre personas del mismo sexo tienen eco en otra corporación de los poderes públicos. 
pues realmente ese requisito debe llamarse "Diferencia de géneros”, que aunque parece una expresión igual a la de "diversidad de sexos", no son categorialmente equivalentes, ya que la primera tiene un marco conceptual y de acción más amplio y la segunda en los mismos aspectos en mucho más restringido y además queda incorporada en la primera categoría. Como ejemplo de la indebida identificación entre género y sexo tomo lo dicho por el tratadista Roberto Suárez Franco ${ }^{10}$ : "De la definición se coligen como características de la unión marital de hecho las siguientes: 1. Diversidad de sexos. La unión marital de hecho, tradicionalmente y tal como se halla prevista en la ley 54 de 1990, es entendible cuando en su conformación intervienen un hombre y una mujer, vale decir, que se configure la diversidad de sexos entre sus componentes. Con acierto el legislador está descartando, como uniones de esta naturaleza, las convenidas por personas de un mismo sexo”. Se ve claramente la confusión hecha por el autor mencionado entre el significado de género y de sexo, interpretando por demás de manera equívoca el sentido que el legislador le quiso dar a los términos hombre y mujer.

Al tomar literalmente, lo que el profesor Hernando Muñoz Sánchez ${ }^{11}$ (15) queda claramente establecido el sentido de diferencia de género a la que se alude en este texto: “...es importante entender que el género es una categoría relacional, es decir, que no es posible estudiar a la mujer y la feminidad, sin la comprensión del hombre y la masculinidad. No se puede hablar de hombre y mujer en singular. Hablemos de la existencia de hombre y mujeres, lo cual evoca pluralidad, diversidad y multiplicidad de identidades masculinas y femeninas que están dadas por la interrelación de varias categorías como: etnia, clase social, edad, generación, historia personal, ser del medio rural o urbano, orientación sexual y religión entre otras. Frente a la naturalización de lo femenino y lo masculino, el desarrollo del concepto de género contribuyó a la comprensión de la cultura como un sistema simbólico que provee a mujeres y hombres una serie de imaginarios, representaciones y prácticas sociales que definen espacios, roles, tiempos y características que ideal y realmente ambos deben cumplir”. Por tanto, desde el año 1990 hasta la actualidad es en este sentido que debe tomarse el concepto de hombre y mujer señalado en el artículo 1 de la susodicha Ley 54; y no como se concebía bajo la ley 45 de 1936 en la que en el concubinato o amancebamiento el hombre y la mujer eran meros sujetos que en los extremos de la relación sexual servían para la complacencia del otro sexo o que buscaban la procreación como un fin de la misma, ya que se justificaba el concubinato como la unión de orden sexual, por ser esa su finalidad esencial al predicarse que su fuente estaba en un mero hecho, el encuentro sexuado protegido por la mutua fidelidad, especialmente la de la concubina, y por la estabilidad, que no significaba en esa época necesariamente la residencia conjunta y el compartir continuo y regular de lecho, techo y mesa, pues se admitía la coexistencia de una relación concubinaria con una relación matrimonial por parte del concubinario,

10 Derecho de Familia, Tomo I, Régimen de las personas, publicado por la Editorial Temis S.A., pág. 438.

11 Investigador de la Universidad de Antioquia, quien realiza un estudio sobre las nuevas masculinidades, al que se refirió en su conferencia dictada en las Segundas Jornadas de Derecho, Género y Sexualidad Universidad EAFIT, realizadas el 7 y 8 de septiembre del año 2009. 
siempre que éste asistiera a la comunidad regular de habitación y proveyera los gastos del hogar común.

Así entonces, hablar de diversidad sexual tiene un componente diferente y más concreto si se quiere que hablar de género, y que aplica perfectamente a las uniones de hecho de diferente sexo y a las de mismo sexo.

En la conferencia "Preferencias sexuales genéricas: heterosexualidad, homosexualidad, bisexualidad: Derrumbe de mitos y falacias”, dictada por la médica y sexóloga Carolina Londoño Gutiérrez, en las ya mencionadas Segundas Jornadas de Derecho Género y Sexualidad, versión 2009, se mostró la consistencia del continuo de la sexualidad humana inicialmente propuesto por el norteamericano Alfred Kinsey y sus colaboradores del Instituto Kinsey, y modificado posteriormente por el grupo de investigadores liderado por el Dr. Lizárraga del Instituto Mexicano de Sexología dirigido por el médico Juan Luis Álvarez-Gayou, quienes ubican en los extremos del continuo la heterosexualidad y la homosexualidad, y en el intermedio la bisexualidad. A partir de ahí denominan seis categorías a saber: "Fundamentalmente heterosexual, básicamente heterosexual, preferentemente heterosexual, bisexual, preferentemente homosexual, básicamente homosexual y fundamentalmente homosexual”; y en otro aparte indica la conferencista: "En este modelo conceptual (no clínico) quedan establecidas 73 posibilidades de expresión hetero y homosexual en un continuo que tiene como extremos a individuos fundamentalmente hetero y homosexuales que son o no practicantes de su potencialidad sexual o quedan en el centro del continuo (que a juicio del Doctor Álvarez-Gayou, podría considerarse el origen) como individuo con potencialidad bisexual, no practicante de su homo ni de su heterosexualidad, es decir el punto donde todos nos encontramos al nacer, como lo planteó Freud”12.

12 El continuo de la sexualidad se explica así: "Fundamentalmente heterosexual: Sólo son atraídos por personas del otro sexo y no es capaz de reconocer belleza en personas de su propio sexo.

Básicamente heterosexual: Reconoce elementos estéticos en individuos de su mismo sexo sin que implique de manera necesaria búsqueda o realización de actividad erótica.

Preferentemente heterosexual: tiene más atracción por personas del otro sexo pero siente también atracción por personas del mismo sexo.

Bisexual: Es el que presenta "no preferencia" es decir que la atracción es igual por uno u otro sexo.

Preferentemente homosexual: tiene más atracción por personas del mismo sexo pero siente también atracción por personas del otro sexo.

Básicamente homosexual: Reconoce elementos estéticos en individuos del otro sexo sin que implique de manera necesaria búsqueda o realización de actividad erótica.

Fundamentalmente homosexual: Sólo son atraídos por personas del mismo sexo y no es capaz de reconocer belleza en personas del otro sexo.

Entonces, existen en consecuencia tres formas de "manifestación de la expresividad sexual hetero y homosexual en cada individuo; así se muestra: Practicante asumido, es decir, el que tiene o ha tenido una u otra actividad y que lo reconoce abiertamente. Oculto u onírico fantasioso, es decir, individuos que pueden fantasear o soñar con una u otra expresividad sin llevarla a cabo, o bien que se encuentran en una etapa de su vida sexual en laque enfrentan a su propia sexualidad y dudan de sus posibilidades de respuesta, sin práctica de esa expresión sexual o con una reducida experiencia. No practicante de una, otra o ambas expresiones. 
Si se quiere entonces, reconocer la obligación que tiene el Estado contemporáneo de reconocer y proteger las diversas manifestaciones culturales, ancestrales, religiosas, sociales y sexuales de sus todos los ciudadanos, máxime el Estado colombiano que se rotula con suficiencia, "Estado social de Derecho" por consagración constitucional, hay suficientes motivos para implementar una legislación general para las uniones maritales de hecho del mismo y de diferente género, o por lo menos una particular para las uniones de hecho entre personas del mismo género y la misma opción sexual.

\section{APOYO BIBLIOGRÁFICO}

\section{Doctrina colombiana}

Medina Pabón, Juan Enrique. Derecho Civil. Aproximación al Derecho de Personas. Bogotá, D.C.: Editorial Universidad del Rosario, segunda edición, 2010. 793 páginas.

Medina Pabón, Juan Enrique. Derecho Civil. .Derecho de Familia. Bogotá, D.C.: Editorial Universidad del Rosario, primera edición, 2008. 838 páginas.

García Restrepo, Álvaro Fernando y Roca Betancur Luz Stella. Unión Marital de Hecho y Sociedad Patrimonial. Bogotá, D.C: ediciones Doctrina y Ley Ltda., 2001. 399 páginas.

García Restrepo, Álvaro Fernando y Roca Betancur Luz Stella. Hacia un justo régimen de bienes entre compañeros permanentes. Medellín: Editorial Semilla Y Viento, 1994. 373 páginas.

Lafont Pianetta, Pedro. Derecho de Familia. Unión Marital de Hecho (Ley 54 de 1990). Santa Fe de Bogotá, D.C.: Ediciones Librería del Profesional, 1992. 569 páginas.

León Jaramillo, Gustavo. Derecho de Familia y de menores. Medellín: Editorial Universidad de Antioquia, 1991. 525 páginas.

Parra Benítez, Jorge. Derecho de Familia. Bogotá: Editorial Temis S.A., 2008. 685 páginas.

Parra Benítez, Jorge. Manual de Derecho Civil. Bogotá: Editorial Temis S.A., 2002. 585 páginas.

Restrepo Múnera, Carolina, Sánchez Pineda, Sandra y Tamayo Sepúlveda Catalina. Derecho y Diversidad Sexual. Medellín: Ediciones Sello Editorial Universidad de Medellín, primera edición, 2010. 231 páginas.

Suárez Franco, Roberto. Derecho de Familia, Tomo I, Régimen de la Personas. Bogotá: Editorial Temis S.A., novena edición, 2006. 495 páginas.

Valencia Zea, Arturo, Ortiz Monsalve, Álvaro. Derecho Civil, Tomo I, Parte General y Personas. Bogotá: Editorial Temis S.A., decimosexta edición, 2006. 679 páginas. 
Valencia Zea, Arturo. Derecho Civil, Tomo V, Derecho de Familia. Bogotá: Editorial Temis S.A., sexta edición, 1998. 607 páginas.

\section{Doctrina española}

Díez Picazo, Luis y Gullón, Antonio. Instituciones de Derecho Civil, Volumen I/1, Introducción. Parte general. Derecho de la Persona. Madrid: Editorial Tecnos S.A., 2000, primera reimpresión de la segunda edición en dos volúmenes, 1998. Páginas 368.

Martínez de Aguirre, Carlos. Acuerdo entre convivientes more uxorio. Conferencia dictada en la Academia Matritense del Notariado, 17 de febrero de 2000. 49 páginas.

Martínez de Aguirre, Carlos. El nuevo matrimonio civil. Ponencia presentada en el Curso Novedades legislativas en materia matrimonial, CGPJ, separata 130, Madrid, 6-8 de septiembre 2006. 58 páginas.

García Cantero, Gabriel y otros. El Matrimonio ¿contrato basura o bien social? Navarra: Editorial Aranzadi, S.A., primera edición, 2008. 250 páginas.

\section{Jurisprudencia}

Corte Constitucional Colombiana, Sentencia T-097 de 1994, M. P. Eduardo Cifuentes Muñoz.

Corte Constitucional Colombiana, Sentencia T-569 de 1994, M. P. Hernando Herrera Vergara.

Corte Constitucional Colombiana, Sentencia T-037 de 1995, M. P. José Gregorio Hernández Galindo.

Corte Constitucional Colombiana, Sentencia T-539 de 1994, M. P. Vladimiro Naranjo Mesa.

Corte Constitucional Colombiana, Sentencia T-290 de 1995, M. P. Carlos Gaviria Díaz.

Corte Constitucional Colombiana, Sentencia C-098 de 1996, M. P. Eduardo Cifuentes Muñoz.

Corte Constitucional Colombiana, Sentencia T-101 de 1998, M. P. Fabio Morón Díaz.

Corte Constitucional Colombiana, Sentencia 481 de 1998, M. P. Alejandro Martínez Caballero.

Corte Constitucional Colombiana, Sentencia C-507 de 1999, M. P. Vladimiro Naranjo Mesa.

Corte Constitucional Colombiana, Sentencia T-618 de 2000, M. P. Alejandro Martínez Caballero. 
Corte Constitucional Colombiana, Sentencia T-999 de 2000, M. P. Fabio Morón Díaz.

Corte Constitucional Colombiana, Sentencia T-1426 de 2000, M. P. Álvaro Tafur Galvis.

Corte Constitucional Colombiana, Sentencia SU-623 de 2001, M. P. Rodrigo Escobar Gil.

Corte Constitucional Colombiana, Sentencia C-814 de 2001, M. P. Marco Gerardo Monroy Cabra.

Corte Constitucional Colombiana, Sentencia C-075 de 2007, M.P. Rodrigo Escobar Gil.

Corte Constitucional Colombiana, Sentencia C-811 de 2007, M.P. Marco Gerardo Monroy Cabra.

Corte Constitucional Colombiana, Sentencia C-336 de 2008, M.P. Clara Inés Vargas Hernández.

Corte Constitucional Colombiana, Sentencia C-338 de 2008, M.P. Clara Inés Vargas Hernández.

Corte Constitucional Colombiana, Sentencia C-029 de 2009, M.P. Rodrigo Escobar Gil. 